Article

\title{
Impact of Water and UV Irradiation on Nonwoven Polylactide/Natural Rubber Fiber
}

\author{
Yulia Tertyshnaya ${ }^{1,2, *(\mathbb{D})}$, Maria Podzorova ${ }^{1,2}$ and Maksim Moskovskiy ${ }^{2}$ \\ 1 Department of Biological and Chemical Physics of Polymers, Emanuel Institute of Biochemical Physics, \\ Russian Academy of Sciences, 4 Kosygina Str., 119334 Moscow, Russia; yersinia@bk.ru \\ 2 Federal Research Agro-Engineering Center VIM, 1st Institutskiy Proezd, 5, 109428 Moscow, Russia; \\ maxmoskovsky74@yandex.ru \\ * Correspondence: terj@rambler.ru; Tel.: +7-916-191-22-72
}

check for

updates

Citation: Tertyshnaya, Y.; Podzorova, M.; Moskovskiy, M. Impact of Water and UV Irradiation on Nonwoven Polylactide/Natural Rubber Fiber. Polymers 2021, 13, 461. https:// doi.org/10.3390/polym13030461

Academic Editor: Hubert Antolak Received: 15 December 2020

Accepted: 28 January 2021

Published: 31 January 2021

Publisher's Note: MDPI stays neutral with regard to jurisdictional claims in published maps and institutional affiliations.

Copyright: (c) 2021 by the authors. Licensee MDPI, Basel, Switzerland. This article is an open access article distributed under the terms and conditions of the Creative Commons Attribution (CC BY) license (https:// creativecommons.org/licenses/by/ $4.0 /)$.

\begin{abstract}
A nonwoven fiber made of polylactide/natural rubber with a rubber content from 0 to $15 \mathrm{wt} . \%$ was obtained by electrospinning from a solution. The water sorption test showed that the addition of natural rubber into the polylactide matrix did not significantly affect the degree of water absorption of the fibers, which was in the range of $48.9-50.6 \%$. The melt flow rate only increased by $0.5 \mathrm{~g} / 10 \mathrm{~min}$ at a content of $15 \mathrm{wt} . \%$ natural rubber. The thermal characteristics after 120 days of degradation in distilled water and UV irradiation $(50 \mathrm{~h})$ at a wavelength of $365 \mathrm{~nm}$ were determined using differential scanning calorimetry. Changes in the values of the phase transition temperatures and the degree of crystallinity were determined. It was determined that the fiber samples from all compositions retained the propensity for photo- and hydrolytic degradation.
\end{abstract}

Keywords: polylactide; non-woven fiber; natural rubber; hydrolytic degradation; UV-irradiation; electrospinning

\section{Introduction}

The modern agricultural sector is in search of innovative materials and technologies to improve the process of crop cultivation, increase productivity, and develop breeding. The use of biodegradable fibrous polymer materials may be suitable for producing seed mats, covering material, air-permeable packaging, etc. [1,2].

Polylactide (PLA) is polyester obtained from renewable raw materials. Lactic acid is released during the fermentation of waste vegetable raw materials: beets, corn, cereals. At the next stage, polylactide is obtained from lactic acid by polymerization [3-5]. Crystalline PLA has properties similar to those of known polymers, such as polypropylene and polyethylene, but they have advantages: biocompatibility and biodegradability [6-9]. Under the influence of environmental agents, PLA decomposes to carbon dioxide and water.

Interest in PLA is only growing, and research on the study of film and fiber materials from PLA is currently being actively conducted [10-12]. Yang et al. [11] studied the morphology of the PLA fibers and their potential in neural tissue engineering. Nicosia et al. reported about the manufacturing of a PLA/PHB fibrous mat with antimicrobial properties for aerosol particle filtration [12]. Ultrathin and nanoscale fiber matrices are of great interest for medicine and the agricultural sector for creating functional materials with biocompatibility, bioresorption, effectiveness and safety properties for living organisms and the environment. The functionality of such materials is due to the high surface-to-volume ratio of an individual fiber. The possibility of modifying its surface is regulated by physical and mechanical characteristics and features of diffusion transport in combination with the use of natural biopolymers. Currently, ultrathin and nonwoven fibers and products from natural biopolymers are actively used in biomedicine, cell engineering, separation and filtration processes, sensory diagnostics, and in a few other areas of science and technology [13-15]. 
One of the most promising methods of producing nano- and micrometer-range fibers is electrospinning, which makes it possible to produce fibers and nonwoven materials from biopolymers. Electrospinning is a multiparametric technological process for producing micro- and nanofibers with a diameter in the range of $10 \mathrm{~nm}-40$ microns. The electrospinning process is subject to a combination of mechanical and electrostatic forces operative on a polymer solution or melt-oriented in an electric field. A number of parameters, such as the voltage at electrodes, the distance between electrodes, and the conductivity, density and viscosity of the molding polymer system, affect the geometry, surface properties, porosity, supramolecular and molecular structure, and fiber functionality $[16,17]$.

The blending of PLA with other polymers is less expensive and more practical. Rubber has been used as a second-phase polymer to toughen brittle thermoplastics. Natural rubber is a high-quality polymer derived from commercial latex, which is obtained from the milky juice of a rubber-bearing plant-Hevea. Natural rubber has been shown to be biodegradable by various mold fungi and a wide range of bacteria $[18,19]$. The repeat unit is 1,4-cis isoprene, and the polymer is widely used to create composite materials [20,21]. Pongtanayut et al. [21] reported that the ductility of PLA was significantly improved by blending it with NR. The amount of NR at $10 \%$ weight seems to give an optimum property. It has been reported that NR may be distributed in the form of flexible nanoscale or submicron formations in a polyolefin matrix to produce composites with a greater elongation than that of the polyolefin [22]. A similar effect was observed when NR was mixed with polylactide to obtain film samples [23]. Xu et al. [23] also found that a reduced PLA phase in the blend and the poor interfacial adhesion between PLA and NR could be the reasons for a decreased tensile strength and hardness. The production and study of PLA/NR fibers has not been reported.

A new composite nonwoven fiber material made from polylactide and natural rubber (NR) has been generated [24]. Nonwoven PLA/NR fiber has an increased elasticity compared to that of pure PLA, while remaining eco-friendly and biodegradable. The current study aims to investigate the influence of environmental factors such as water and UV irradiation on the degradation of PLA/NR fiber.

\section{Materials and Methods}

Polylactide $4032 \mathrm{D}$ with a molecular weight of $1.7 \times 10^{5} \mathrm{~g} / \mathrm{mol}$ and $\rho=1.24 \mathrm{~g} / \mathrm{cm}^{3}$ produced by Nature works (Minnetonka, MN, USA) as well as natural rubber SVR $3 \mathrm{~L}$ from Vietnam Rubber Group (Ho Chi Minh City, Vietnam) were used. The natural rubber consisted of poly(cis-1,4-isoprene), with minor impurities from other compounds and water (Table 1) [25].

Table 1. Chemical composition of natural rubber (NR), grade SVR 3 L.

\begin{tabular}{cc}
\hline Substance & Content, wt. $\%$ \\
\hline Poly(cis-1,4-isoprene) & $91-96$ \\
Protein and amino acids & $2-3$ \\
Resins & $2-3$ \\
Soot indicator & 0.5 \\
Volatiles & 0.8 \\
Transition metal compounds & $<1$ \\
Other & $<1$ \\
\hline
\end{tabular}

The polymer solutions for electrospinning were prepared by dissolving PLA and PLA/NR in the right ratio in chloroform. The mixtures were heated at $60{ }^{\circ} \mathrm{C}$ for about 4-5 min. The polymer solution was placed in a syringe with a needle inner diameter of $0.7 \mathrm{~mm}$, set up vertically. The electrospinning experiments were performed at room temperature $\left(20 \pm 2{ }^{\circ} \mathrm{C}\right)$. The consumption of the solution was $(9-11) \times 10^{5} \mathrm{~g} / \mathrm{s}$. The content of natural rubber in the mixture was $0,5,10$, and $15 \mathrm{wt} . \%$

The kinetics of distilled water absorption by the samples was studied for $240 \mathrm{~h}$ after the materials reached equilibrium water absorption (GOST 4650-2014 (ISO 62:2008)). Square 
samples with a side of $30 \mathrm{~mm}$ were used for testing. The test was performed for five samples of each composition. Before the test, the samples were dried at $(40 \pm 2){ }^{\circ} \mathrm{C}$ for $24 \mathrm{~h}$ and then cooled in a desiccator over a desiccant at $(22 \pm 2)^{\circ} \mathrm{C}$ and weighed no more than $5 \mathrm{~min}$ after removal from the desiccator. Furthermore, the samples were placed in a vessel with distilled water taken in an amount of at least $8 \mathrm{~cm}^{3}$ per $1 \mathrm{~cm}^{2}$ of the sample surface. The test samples were not allowed to be in contact with each other or the walls of the vessel, and were completely covered with water. The liquid was agitated by rotating the vessel at least once a day.

When determining the maximum water absorption, the equilibrium was considered reached if the difference between the sample mass, determined at an interval of $24 \mathrm{~h}$, did not exceed $0.1 \%$.

After an equilibrium amount of water in the sample was established, it was removed from the water, dried with a filter paper, and weighed using an electronic balance no more than 1 min later.

The degree of water absorption was calculated as (1):

$$
W=\frac{\left(m_{2}-m_{1}\right)}{m_{1}} \times 100 \%
$$

where $m_{1}$-initial mass of the sample, and $m_{2}$-mass of the sample after water influence.

The resistance of the samples to photodegradation was studied using a UV radiation source VL-6.LC from the company Viber Lourmat (France). The wavelength was $365 \mathrm{~nm}$. The distance from the lamp to the samples was $15 \mathrm{~cm}$.

The melt flow rate (MFR) was determined in accordance with GOST 11645-73 (ISO 1133-76) on the device IIRT-5 (Russia), which was based on the principle of a capillary viscometer.

The thermophysical characteristics of the samples were determined by differential scanning calorimetry (DSC) using a DSC 204 F1 device (Netzsch, Selb, Germany). The scanning speed was $8 \mathrm{deg} / \mathrm{min}$, the weight was varied in the range of $5-5.5 \mathrm{mg}$, and the calibration was performed for indium with a melting point $\mathrm{T}_{\mathrm{m}}=156.6^{\circ} \mathrm{C}$. The accuracy of the measurement was $\mathrm{T}=0.1^{\circ} \mathrm{C}$. The temperatures of melting and crystallization $\left(\mathrm{T}_{\mathrm{m}}\right.$ and $\mathrm{T}_{\mathrm{c}}$ ) were determined by an endothermic maximum of the melting peak and an exothermic maximum of the crystallization peak on DSC thermograms, respectively

The value of the degree of crystallinity $\chi_{c r}$ was calculated by Formula (2):

$$
\chi_{c r}=\frac{\Delta H_{m}}{\Delta H_{m}^{*}} \times 100 \%
$$

where $\Delta H_{m}^{*}$-enthalpy of melting of the ideal crystal, which was $93 \mathrm{~J} / \mathrm{g}$ for PLA [3].

The thermogravimetric analysis (TGA) of the samples was carried out in argon on a TG 209 F1 thermoanalytical balance (Netzsch, Germany) at a heating rate of $20 \mathrm{~K} / \mathrm{min}$.

The experimental results were calculated as the arithmetic mean and its standard error. The calculations were performed using Statistica 8.0 software (Dell Software Inc., Round Rock, TX, USA) and Microsoft Excel 2007.

\section{Results}

The PLA/NR agrofiber of various compositions was obtained from the solution by electrospinning. PLA/NR nonwoven fiber (Figure 1) can be used in agricultural applications as seed mats or covering material, for example to protect the breeding seeds of experimental crops from birds and adverse weather. 


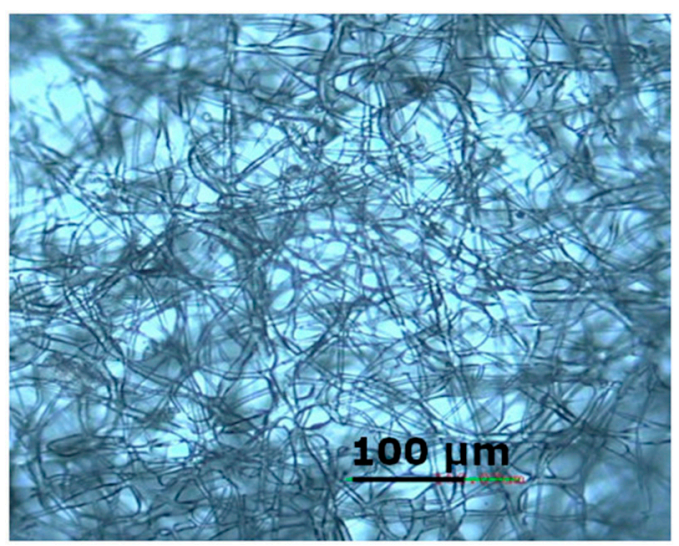

(a)

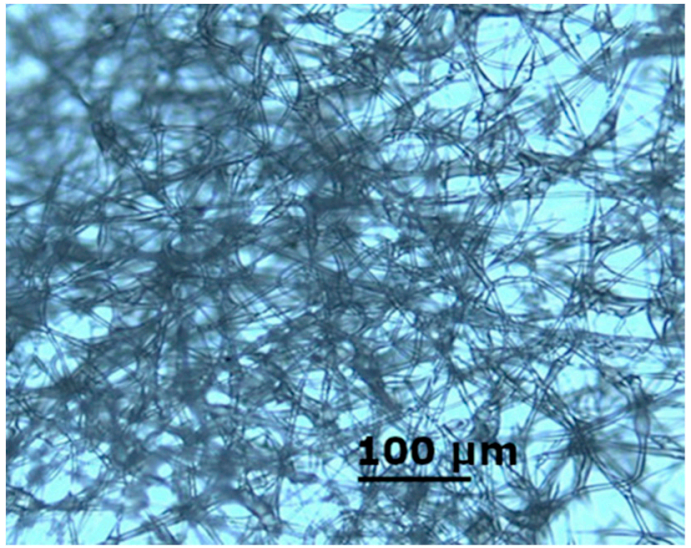

(b)

Figure 1. Microphotos of nonwoven fiber: (a) 100\% PLA and (b) 95\% PLA/5\% NR. Magnification of 100 times.

When using any polymer materials, both film and fiber, it is important to know the rheological properties, so for all samples of nonwoven PLA/NR fiber, the melt flow rate (MFR) was determined (Figure 2).

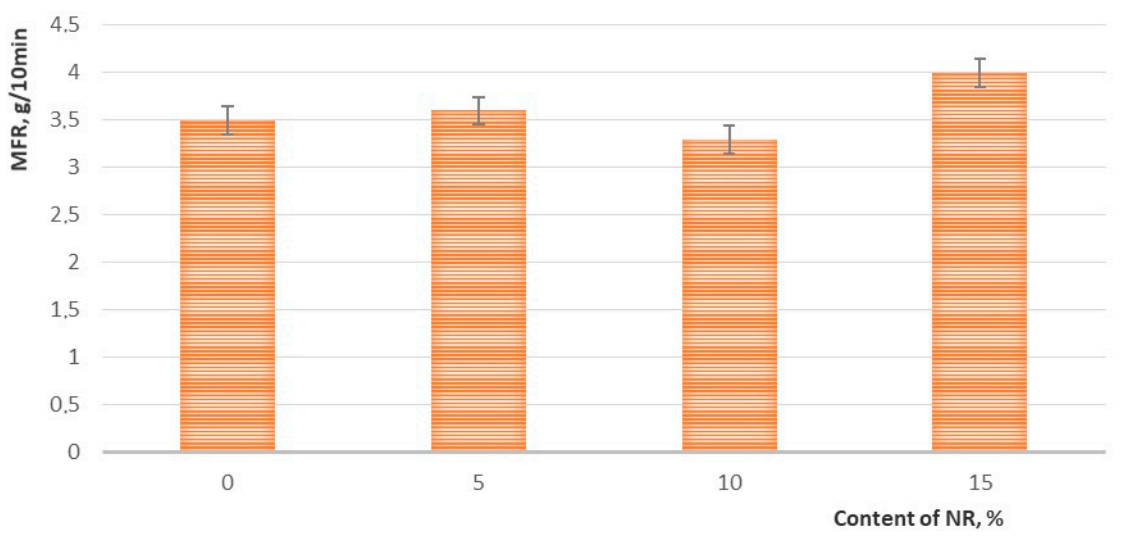

Figure 2. Melt flow rate of samples of nonwoven PLA/NR fiber containing 0, 5, 10, and 15 wt.\% of NR.

As the experiment showed, the addition of natural rubber did not significantly affect the MFR of PLA/NR samples; only when the NR content was $15 \mathrm{wt} . \%$ did the MFR increase by $0.5 \mathrm{~g} / 10 \mathrm{~min}$, which was a completely acceptable change in MFR for polymer compositions.

When using fiber in open ground conditions, the main environmental agents affecting PLA/NR fiber will be water and ultraviolet irradiation. The water absorption test allows one to determine the equilibrium amount of water absorbed by the material under certain conditions. The water adsorption by polymers depends on many components. For example, the degree of crystallinity and the temperature play an important role. The degree of water absorption is very dependent on the type of material. It is obvious that due to the porous structure, the fiber absorbs more water than the film. In this case, it is the type of material that plays the main role, and not the hydrophilicity or hydrophobicity of the polymers in the composite. The experiment showed that the addition of natural rubber had almost no effect on the degree of water absorption $W$ (Figure 3). 


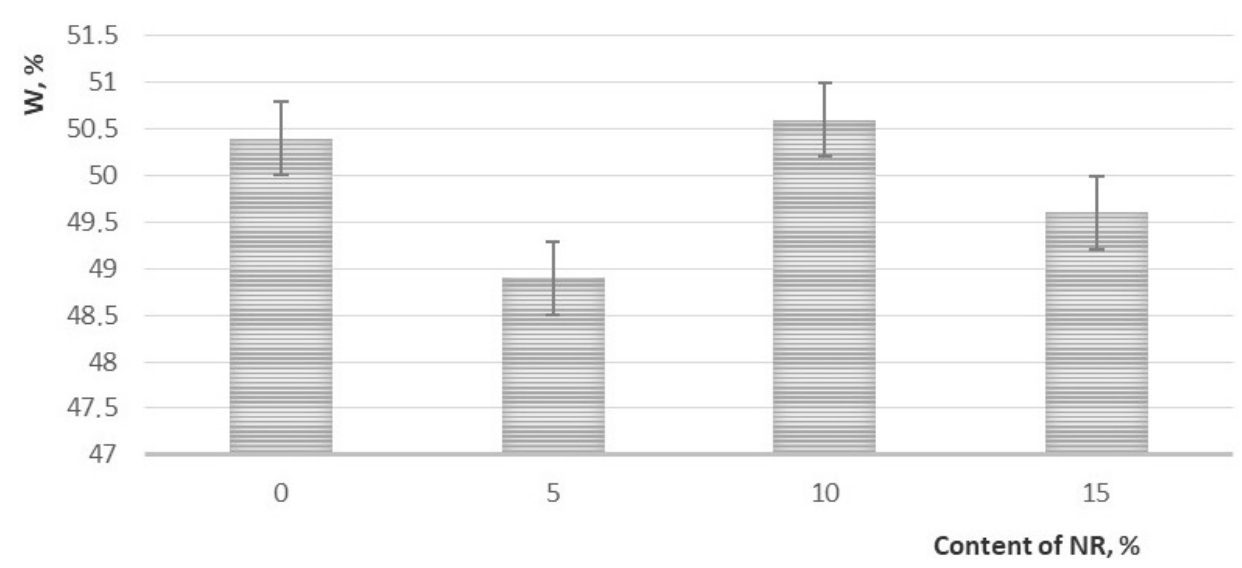

Figure 3. Degree of water absorption (W, \%) of samples of nonwoven PLA/NR fiber containing $0,5,10$, and 15 wt. $\%$ of NR.

Water is one of the most aggressive environmental factors. A large number of investigations have been performed on the hydrolytic degradation behavior of PLA films in aqueous medium [26-30]. As for the long-term exposure to the aqua environment, many studies have shown the hydrolytic degradation of polylactide according to the Scheme $1[30,31]$ :<smiles>CCCOC(=O)C(C)C</smiles>

Scheme 1. PLA hydrolysis.

Hydrolysis of PLA occurs by the addition-elimination of a complex carbonyl induced by water, and then water-soluble oligomers and monomers are produced. In the process of hydrolytic degradation, the samples turn white. Such an effect was also observed for PLA/NR fibers.

When studying the effect of water on nonwoven fiber PLA/NR during 180 days, it was determined that after hydrolytic degradation on the melting thermograms, the melting temperature $\left(\mathrm{T}_{\mathrm{m}}\right)$ of PLA/NR samples changed insignificantly and the glass transition peak of PLA almost disappeared (Figure 4). Such a behavior of $T_{g}$ is attributable to a decrease in the molecular weight [26].

An increase in the PLA degree of crystallinity is a consequence of the disintegration of the amorphous phase and a possible decrease in the molecular weight (Table 2). The remaining PLA chains then have a higher mobility, and they can reorganize themselves more easily, which leads to an increase in the degree of crystallinity $[27,29]$.

Table 2. Thermophysical characteristics of PLA/NR nonwoven fiber samples: initially and after 180 days of water degradation.

\begin{tabular}{|c|c|c|c|c|c|c|}
\hline \multirow[t]{2}{*}{ NR, wt. $\%$} & \multicolumn{3}{|c|}{ Initial Samples } & \multicolumn{3}{|c|}{ After Water Influence for 180 Days } \\
\hline & $\begin{array}{c}\mathrm{T}_{\mathrm{g}},{ }^{\circ} \mathrm{C} \\
\left(\Delta \pm 0.5^{\circ} \mathrm{C}\right)\end{array}$ & $\begin{array}{c}\mathrm{T}_{\mathrm{m}},{ }^{\circ} \mathrm{C} \\
\left(\Delta \pm 0.5^{\circ} \mathrm{C}\right)\end{array}$ & $\begin{array}{c}\chi_{\mathrm{cr}}, \% \\
(\Delta \pm 1 \%)\end{array}$ & $\begin{array}{c}\mathrm{T}_{\mathrm{g}},{ }^{\circ} \mathrm{C} \\
\left(\Delta \pm 0.5^{\circ} \mathrm{C}\right)\end{array}$ & $\begin{array}{c}\mathrm{T}_{\mathrm{m}},{ }^{\circ} \mathrm{C} \\
\left(\Delta \pm 0.5^{\circ} \mathrm{C}\right)\end{array}$ & $\begin{array}{c}\chi_{\mathrm{cr}}, \% \\
(\Delta \pm 1 \%)\end{array}$ \\
\hline 0 & 61 & 164 & 34 & - & 168 & 46 \\
\hline 5 & 63 & 168 & 36 & - & 167 & 46 \\
\hline 10 & 66 & 167 & 38 & - & 167 & 47 \\
\hline 15 & 65 & 166 & 37 & - & 166 & 47 \\
\hline
\end{tabular}




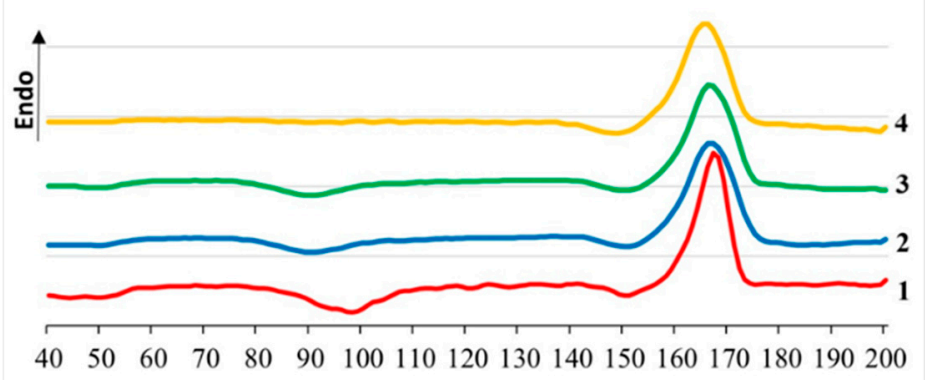

Temperature, ${ }^{\circ} \mathrm{C}$

Figure 4. Melting thermograms of nonwoven PLA/NR fibers with different NR contents: (1) 0, (2) 5 , (3) 10, and (4) 15 wt.\%. 180 days of water degradation. DSC method.

Figure 5 shows typical mass loss curves, which are similar for all the fiber samples. The TGA data confirm the effect of water on PLA/NR fibers. After the experiment, the mass loss occurs at a lower temperature when compared to the initial sample. The maximum degradation temperature is shifted by $10-13^{\circ} \mathrm{C}$ toward low temperatures for all the fiber samples.

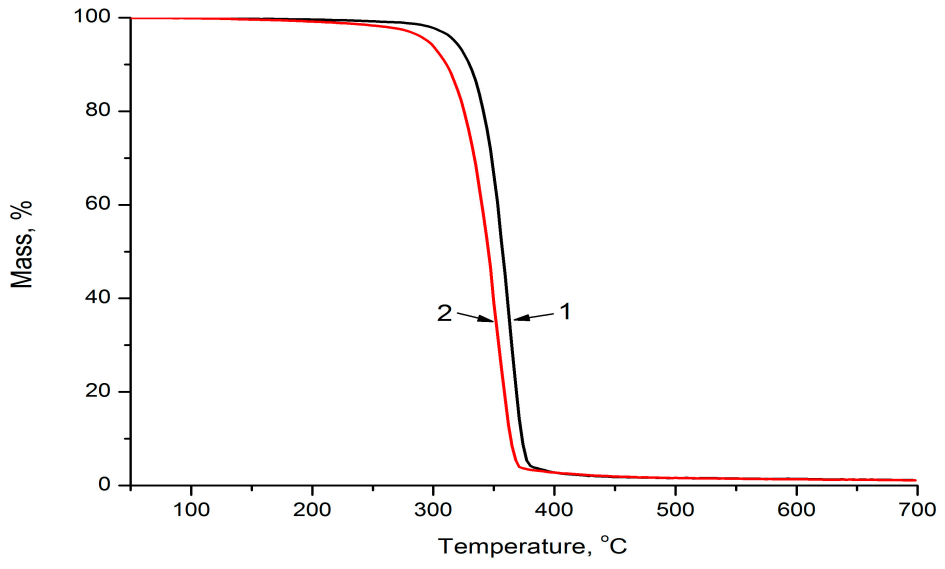

Figure 5. TGA thermograms of PLA/NR samples with 10\% wt. of NR content: 1-initial, and 2-after 180 days of hydrolytic degradation.

UV radiation is another aggressive environmental factor. During photo-destructive processes, polymers and the products that are made from them change various properties and colors and lose their performance characteristics [32,33]. When studying the effect of UV radiation on polymer materials, irradiators with different wavelengths are used. The most active part of the UV spectrum does not reach the earth's surface, but radiation in the range of $270-400 \mathrm{~nm}$ affects all creatures and objects, so researchers often use ultraviolet sources with wavelengths from the above range in model tests.

In this part of the study, it is important to determine the effect of NR on the photodegradation of nonwoven fiber samples, and the addition of NR increases or decreases the resistance of nonwoven fibers to UV radiation, which is very important for covering material used in open-ground conditions. The effect of UV irradiation on fiber was evaluated using the DSC method. Figure 6 shows the thermograms of the initial samples of PLA/NR fibers and after UV irradiation for 20 and $50 \mathrm{~h}$. Table 3 shows the thermophysical characteristics of nonwoven fiber PLA/NR from different compositions after the influence of UV radiation. 


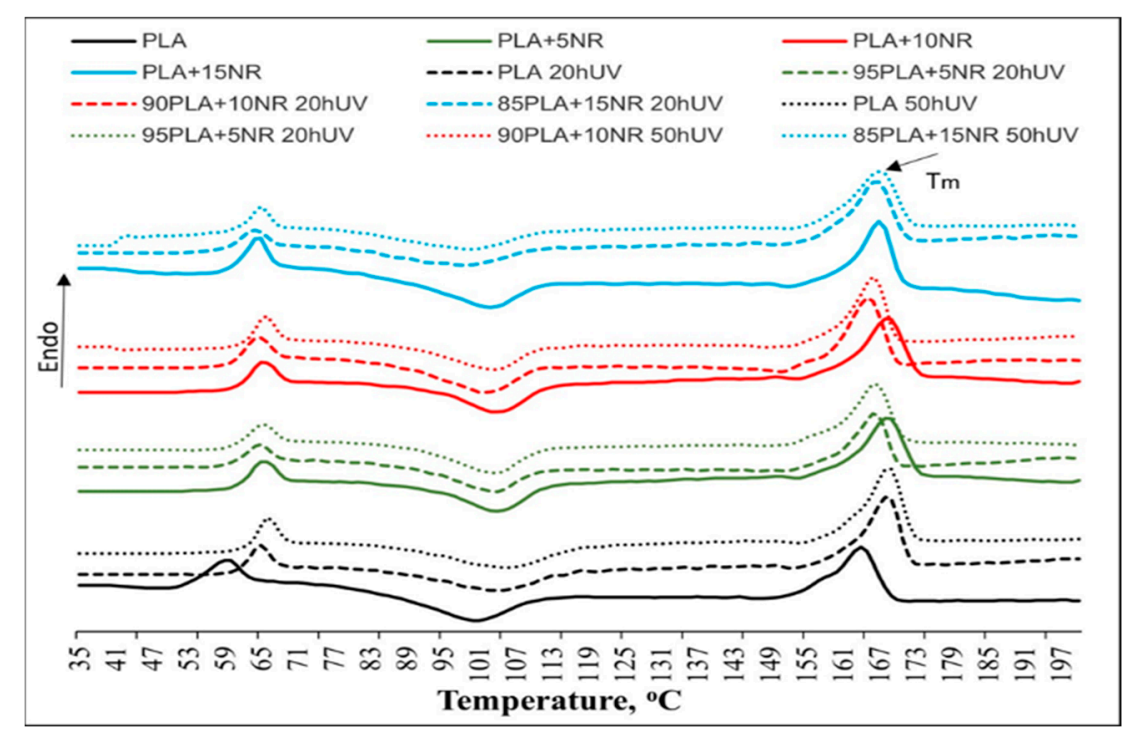

Figure 6. Thermograms of PLA/NR agrofiber samples from various compositions: initially and after $\mathrm{UV}$ radiation; $\lambda=365 \mathrm{~nm}$ for 20 and $50 \mathrm{~h}$. The DSC method.

Table 3. Thermophysical characteristics of PLA/NR nonwoven fiber samples: before and after 20 and $50 \mathrm{~h}$ of UV-irradiation exposure $(\lambda=365 \mathrm{~nm})$.

\begin{tabular}{|c|c|c|c|c|c|c|c|c|c|c|c|c|}
\hline \multirow[t]{2}{*}{$\begin{array}{l}\text { NR, } \\
\text { wt. } \%\end{array}$} & \multicolumn{3}{|c|}{$\mathrm{T}_{\mathrm{g}},{ }^{\circ} \mathrm{C}\left(\Delta \pm 0.5^{\circ} \mathrm{C}\right)$} & \multicolumn{3}{|c|}{$\mathrm{T}_{\mathrm{m}},{ }^{\circ} \mathrm{C}\left(\Delta \pm 0.5^{\circ} \mathrm{C}\right)$} & \multicolumn{3}{|c|}{$\mathrm{T}_{\mathrm{c}},{ }^{\circ} \mathrm{C}\left(\Delta \pm 0.5^{\circ} \mathrm{C}\right)$} & \multicolumn{3}{|c|}{$\chi_{\mathrm{cr}}, \%(\Delta \pm 1 \%)$} \\
\hline & $0 \mathrm{~h}$ & $20 \mathrm{~h}$ & $50 \mathrm{~h}$ & $0 \mathrm{~h}$ & $20 \mathrm{~h}$ & $50 \mathrm{~h}$ & $0 \mathrm{~h}$ & $20 \mathrm{~h}$ & $50 \mathrm{~h}$ & $0 \mathrm{~h}$ & $20 \mathrm{~h}$ & $50 \mathrm{~h}$ \\
\hline 0 & 60 & 66 & 67 & 164 & 168 & 169 & 101 & 104 & 106 & 33 & 38 & 40 \\
\hline 5 & 65 & 65 & 66 & 168 & 167 & 166 & 105 & 104 & 103 & 36 & 38 & 38 \\
\hline 10 & 66 & 63 & 65 & 169 & 163 & 167 & 105 & 102 & 104 & 37 & 39 & 39 \\
\hline 15 & 65 & 65 & 66 & 168 & 165 & 167 & 104 & 103 & 101 & 36 & 37 & 38 \\
\hline
\end{tabular}

From the DSC data, it follows that when exposed to UV radiation, the glass transition temperature $\left(\mathrm{T}_{\mathrm{g}}\right)$ of the PLA changes ambiguously. In pure PLA, the $\mathrm{T}_{\mathrm{C}}$ increases by $7^{\circ} \mathrm{C}$, while the $\mathrm{T}_{\mathrm{m}}$ increases by $6{ }^{\circ} \mathrm{C}$ and the degree of crystallinity increases by $7 \%$. In samples of nonwoven fiber PLA/NR of the PLA, the $\mathrm{T}_{\mathrm{g}}$ changes slightly, and the melting and crystallization temperature decreases by $2-3{ }^{\circ} \mathrm{C}$.

The $\mathrm{T}_{\mathrm{g}}$ of pure PLA fiber increases after 20 and $50 \mathrm{~h}$ of the experiment. This is an interesting fact. Usually, PLA photodegradation is accompanied by a decrease of the $\mathrm{T}_{\mathrm{g}}$ value. It is possible that the effect of UV irradiation $(\lambda=365 \mathrm{~nm})$ for $50 \mathrm{~h}$ causes an annealing effect, in which $T_{g}, T_{m}$, and the degree of crystallinity increase. The experiment will be continued. Perhaps after 150 or $250 \mathrm{~h}$ of photodegradation, the thermal characteristics of pure PLA fiber will start to decrease.

\section{Discussion}

Interfacial interactions in the "polymer-polymer" systems are of great importance in matters of structure formation, in particular the effect of amorphous polymer-rubber on the structure and properties of crystallizing PLA. The thermophysical characteristics of initial PLA/NR nonwoven fiber were represented (Table 2). The results confirmed the immiscible behavior of the fiber composites, since almost no changes were observed in the glass transition temperature $\left(\mathrm{T}_{\mathrm{g}}\right)$ of PLA with the NR content. It was observed that the addition of NR with a content of $5-15 \%$ wt. increased the degree of PLA crystallinity by $2-4 \%$.

Adding rubber at an amount of 30-50 wt.\% in the matrix of the crystallizing polymer [34] can significantly affect the structure and properties of the composite. In mixtures containing 30-50 wt.\% of the second component, a phase inversion often occurs. In this 
case, the dielectric, mechanical, and rheological properties will be determined by the characteristics of the second component. Therefore, to improve elasticity and maintain the other characteristics of thermoplastics, the rubber additive should be in the range of $20-25 \%$.

Regarding the influence of aggressive environments on polymers and polymer composites, such studies will be relevant if there are new promising polymer materials. The effect of water on polymers has been studied since the middle of the last century [35]. Water plays a crucial role in biological processes but can adversely affect the performance of polymers. It has been established that the hydrolysis of PLA begins with the diffusion of water molecules into amorphous regions. After that, the degradation continues in the boundary layers of the crystal domains [36]. The hydrolytic degradation of PLA has been studied quite extensively [37-39]. The current study shows that the adding of NR at a content of 5-15 wt.\% into the PLA matrix practically does not affect the degree of water absorption of fibrous samples and does not prevent the degradation of nonwoven PLA/NR fibers, which is confirmed by the DSC and TGA data.

Ultraviolet irradiation is a powerful aggressive factor that causes the aging of polymers, as well as changes in their color, structure, and performance properties. The absorbing centers are most often carbonyl and other oxygen-containing groups. In the presence of oxygen, light initiates a chain oxidative reaction, radicals are formed, and then the process proceeds by a radical mechanism, like the process of thermal-oxidative degradation.

In [40], the photodegradation of PLA-based nanocomposites with the addition of polycaprolactone and montmorillonite (wavelength $254 \mathrm{~nm}$ ) was studied. As a result of research [38], it was found that the PLA was actively exposed to ultraviolet light. After $16 \mathrm{~h}$, the molecular weight decreased, and the polylactide was destroyed. The addition of montmorillonite delayed the photodegradation rate of the polylactide. The analysis of the accumulation of acetic anhydride by IR spectroscopy suggests that the pure polylactide is degraded faster than the investigated composites. The study of the photodegradation of film samples of pure PLA and its mixtures with PE under the same conditions showed a rapid disintegration of not only the amorphous but also the crystalline phase of PLA [25].

It should be noted that irradiation with a wavelength of $254 \mathrm{~nm}$ is a model medium. In this work, no rapid degradation of the PLA crystal phase was observed. A wavelength of $365 \mathrm{~nm}$ was used, which corresponded to a softer radiation, so under these conditions, the disintegration of the amorphous phase and an increase in the degree of PLA crystallinity in fibrous PLA/NR samples could be observed over $50 \mathrm{~h}$ of ultraviolet light. Further investigation of photodegradation under the above conditions will allow one to estimate the effect of irradiation under milder conditions and to compare the obtained data with those from irradiation with a wavelength of $254 \mathrm{~nm}$.

\section{Conclusions}

Promising and biobased nonwoven PLA/NR fiber was obtained by electrospinning with an NR content of 5-15 wt.\%. The addition of NR to the PLA matrix leads to a slight increase of the melting temperature and the degree of crystallinity.

It was determined that the addition of NR into the PLA matrix only increased the MFR value by $0.5 \mathrm{~g} / 10 \mathrm{~min}$ at $15 \mathrm{wt} . \%$. All samples of PLA/NR have a similar degree of water absorption. NR has no observable effect on the hydrolysis of PLA, which would be beneficial for the biodegradation of PLA modified by NR.

Regardless of the content of NR, all samples of PLA/NR fibers retain the ability for hydrolytic degradation and photodegradation, which is a very important aspect for potential use in agricultural applications such as covering materials or seed mats, which should be ecofriendly.

Author Contributions: Conceptualization, Y.T.; methodology, Y.T.; software, M.P.; validation, Y.T.; formal analysis, Y.T.; investigation, M.P.; resources, M.M.; data curation, Y.T.; writing-original draft preparation, Y.T. and M.P.; writing—review and editing, Y.T.; visualization, M.P.; supervision, Y.T.; project administration, Y.T. and M.M.; funding acquisition, M.M. All authors have read and agreed to the published version of the manuscript. 
Funding: This research received no external funding.

Acknowledgments: The research was supported by the Ministry of Science and Higher education of the Russian Federation, the contract № 1201253305 (research project 44.3: “Polymer Materials Science: Kinetics and Mechanisms of Chemical and Physical Processes in Polymers, Composites, and Biological Systems").

Conflicts of Interest: The authors declare no conflict of interest. The funders had no role in the design of the study; in the collection, analyses, or interpretation of data; in the writing of the manuscript, or in the decision to publish the results.

\section{References}

1. Lee, S.H.; Wang, S. Biodegradable polymers/bamboo fiberbiocomposite with biobased coupling agent. Compos. A Appl. Sci. Manuf. 2006, 37, 80-91. [CrossRef]

2. Graupner, N.; Herrmann, A.S.; Mussig, J. Natural and man-made cellulose fibre-reinforced poly (lactic acid) (PLA) composites: An overview about mechanical characteristics and application areas. Compos. Part A 2009, 40, 810-821. [CrossRef]

3. Lim, L.-T.; Auras, R.; Rubino, M. Processing technologies for poly(lactic acid). Prog. Polym. Sci. 2008, 33, 820. [CrossRef]

4. Garlotta, D. A literature review of polylactid acid. J. Polym. Environ. 2001, 9, 63-84. [CrossRef]

5. Podzorova, M.V.; Tertyshnaya, Y.V.; Popov, A.A. Environmentally friendly films based on poly(3-hydroxybutyrate) and poly(lactic acid): A review. Rus. J. Phys. Chem. B 2014, 8, 726-732. [CrossRef]

6. Holm, V.K.; Ndoni, S.; Risbo, J. The stability of poly(lactic acid) packaging films as influenced by humidity and temperature. J. Food Sci. 2006, 71, 40-44. [CrossRef]

7. Piemonte, V.; Gironi, F. Kinetics of hydrolytic degradation of PLA. J. Polym. Environ. 2013, 21, 313-318. [CrossRef]

8. Tertyshnaya, Y.V.; Popov, A.A. Hydrolytic degradation of polylactide in distilled water and seawater. Polym. Sci. Ser. D 2020, 13, 306-310. [CrossRef]

9. Tertyshnaya, Y.V.; Levina, N.S.; Popov, A.A.; Moskovskii, M.N.; Izmailov, A.Y. Hydrolytic destruction of agrofiber made of natural polymers. Fibre Chem. 2019, 51, 117-120. [CrossRef]

10. Tertyshnaya, Y.V.; Lobanov, A.V.; Karpova, S.G.; Pantyukhov, P.V. Composites based on polylactide and manganese (III) tetraphenylporphyrin. Influence of concentration on the structure and properties. J. Mol. Liq. 2020, 302, 112176. [CrossRef]

11. Yang, F.; Murugan, R.; Wang, S.; Ramakrishna, S. Electrospinning of nano/micro scale poly(L-lactic acid) aligned fibers and their potential in neural tissue engineering. Biomaterials 2005, 26, 2603-2610. [CrossRef]

12. Nicosia, A.; Gieparda, W.; Foksowicz-Flaczyk, J.; Walentowska, J.; Wesolek, D.; Vazquez, B.; Prodi, F.; Belosi, F. Air filtration and antimicrobial capabilities of electrospun PLA/PHB containing ionic liquid. Separ. Purif. Tech. 2015, 154, 154-160. [CrossRef]

13. Karpova, S.G.; Ol'khov, A.A.; Popov, A.A.; Zhul'kina, A.L.; Iordanskii, A.L. Analysis of the structure of ultrafine fibers based on poly(3-hydroxybutyrate) and polylactide: Effect of external factors. Polym. Sci. Ser. A 2019, 61, 480-490. [CrossRef]

14. Jia, W.; Gong, R.H.; Hogg, P.J. Poly(lactic acid) fibre reinforced biodegradable composites. Compos. Part B 2014, 62, 104-112. [CrossRef]

15. Kaur, S.; Sundarrajan, S.; Rana, D.; Matsuura, T.; Ramakrishna, S. Influence of electrospunfiber size on the separation efficiency of thin film nanofiltration composite membrane. J. Membr. Sci. 2012, 392-393, 101-111. [CrossRef]

16. Casasola, R.; Thomas, N.L.; Trybala, A.; Georgiadou, S. Electrospun poly lactic acid (PLA) fibres: Effect of different solvent systems on fibre morphology and diameter. Polymer 2014, 55, 4728-4737. [CrossRef]

17. Jun, Z.; Hou, H.; Schaper, A.; Wendorff, J.H.; Greiner, A. Poly-L-lactidenanofibers by electrospinning-influence of solution viscosity and electrical conductivity on fiber diameter and fiber morphology. E-Polymers 2003, 3, 102-110.

18. Bode, H.B.; Kerkho, K.; Jendrossek, D. Bacterial Degradation of Natural and Synthetic Rubber. Biomacromolecules 2001, 2, $295-303$. [CrossRef]

19. Steinbüchel, L.A. Biodegradation of Natural and Synthetic Rubbers; Wiley-VCH Verlag GmbH \& Co. KGaA: Münster, Germany, 2005.

20. Sia, W.-L.; Yuana, W.-Q.; Lia, Y.-D.; Chenb, Y.-K.; Zengabc, J.-B. Tailoring toughness of fully biobased poly(lactic acid)/natural rubber blends through dynamic vulcanization. Polym. Test. 2018, 65, 249-255. [CrossRef]

21. Pongtanayut, K.; Thongpin, C.; Santawitee, O. The effect of rubber on morphology, thermal properties and mechanical properties of PLA/NR and PLA/ENR blends. Energy Proced. 2013, 34, 888-897. [CrossRef]

22. Yáfiez-Flores, I.G.; Ramos-DeValle, L.F.; Rodriguez-Fernandez, O.S.; Sánchez-Valdez, S. Blends of Polyethylene-Polyisoprene Rubbers: Study of Flow Properties. J. Polym. Eng. 1997, 17, 295-310.

23. Xu, C.; Yuan, D.; Fu, L.; Chen, Y. Physical blend of PLA/NR with co-continuous phase structure: Preparation, rheology property, mechanical properties and morphology. Polym. Test. 2014, 37, 94-101. [CrossRef]

24. Tertyshnaya, Y.V.; Shibryaeva, L.S. Biodegradable Fiber Composite Based on Polylactide and Its Application for the Plants Growing. RU Patent Application No 2734883 C1, 23 October 2020.

25. Erman, B.; Mark, J.E.; Roland, C.M. Science and Technology of Rubber, 3rd ed.; Elsevier Inc. Academic Press: Waltham, MA, USA, 2005.

26. Saha, S.K.; Tsuji, H. Effect of molecular weight and small amount of D-lactide units on hydrolytic degradation of poly(L-lactic acid)s. Polym. Degrad Stab. 2006, 91, 1665-1673. [CrossRef] 
27. Fukushima, K.; Tabuani, D.; Dottori, M.; Armentano, I.; Kenny, J.M.; Camino, G. Effect of temperature and nanoparticle type on hydrolytic degradation poly(lactic acid) nanocomposites. Polym. Degrad Stab. 2011, 96, 2120-2129. [CrossRef]

28. Tsuji, H.; Suzuyoshi, K. Environmental degradation of biodegradable polyesters 1. Poly(caprolactone), poly[(R)-3hydroxybutyrate], and poly(L-lactide) films in controlled static seawater. Polym. Degrad Stab. 2002, 75, 347-355. [CrossRef]

29. Deroine, M.; Le Duigou, A.; Corre, Y.-M.; Le Gac, P.-Y.; Davies, P.; Cesar, G.; Bruzaud, S. Accelerated aging of polylactide in aqueous environment: Comparative study between distilled water and seawater. Polym. Degrad. Stab. 2014, 108, 319-329. [CrossRef]

30. Olewnik-Kruszkowska, E. Influence of the type of buffer solution on thermal and structural properties of polylactide-based composites. Polym. Degrad. Stab. 2016, 129, 87-95. [CrossRef]

31. Jin, F.-L.; Hu, R.-R.; Park, S.-J. Improvement of thermal behaviors of biodegradable poly(lactic acid) polymer: A review. Comp. Part B 2019, 164, 287-296. [CrossRef]

32. Tertyshnaya, Y.V.; Podzorova, M.V. Effect of UV Irradiation on the Structural and Dynamic Characteristics of Polylactide and Its Blends with Polyethylene. Rus. J. Phys. Chem. B 2020, 14, 167-175. [CrossRef]

33. Bocchini, S.; Fukushima, K.; Di Blasio, A.; Fina, A.; Geobaldo, F.F. Polylactic acid and polylactic acid-based nanocomposite photooxidation. Biomacromolecules 2010, 11, 2919-2926. [CrossRef]

34. Ol'khov, A.A.; Tertyshnaya, Y.V.; Shibryaeva, L.S.; Iordanskii, A.L.; Zaikov, G.E. The structure and properties of blends of poly(3hydroxybutyrate) with an ethylene-propylene copolymer. In Chemical Process in Liquid and Solid Phase: Properties, Performance and Applications; Apple Academic Press: Nova, France, 2013; pp. 65-74.

35. Rowland, S.P. Water in Polymers; ACS Symp Series 127; ACS Publishing Center: Washington, DC, USA, 1980.

36. Auras, R.; Lim, L.-T.; Selke, S.; Tsuji, H. Poly(Lactic Acid). Synthesis, Structures, Properties, Processing, and Applications: Hydrolytic Degradation; John Wiley \& Sons, Inc.: New Jersey, NJ, USA, 2010; pp. 345-381.

37. Tertyshnaya, Y.V.; Karpova, S.G.; Popov, A.A. Effect of Aqueous Medium on the Molecular Mobility of Polylactide. Rus. J. Phys. Chem. B 2017, 11, 531-537. [CrossRef]

38. Huang, Y.; Zhang, C.; Pan, Y.; Zhou, Y.; Jiang, L.; Dan, Y. Effect of natural rubber on the hydrolytic degradation of polylactide. Polym. Degrad. Stab. 2013, 9, 943-950. [CrossRef]

39. Avinc, O.; Khoddami, A. Overview of poly(lactic acid) PLA fibre, Part I: Production, Properties, Performance, Environmental Impact, and End-use Applications of Poly(lactic acid) Fibres. Fibre Chem. 2009, 41, 391-401. [CrossRef]

40. Olewnik-Kruszkowska, E.; Koter, I.; Skopinska-Wisniewskab, J.; Richert, J. Degradation of polylactide composites under UV irradiation at $254 \mathrm{~nm}$. J. Photochem. Photobiol. A Chem. 2015, 311, 144-153. [CrossRef] 